05

\title{
Выращивание объемных кристаллов оксида галлия из расплава методом Чохральского в кислородсодержащей атмосфере
}

\author{
(ㄱ Д.А. Закгейм ${ }^{1,2}$, Д.Ю. Панов ${ }^{1, \uparrow, ~ В . А . ~ С п и р и д о н о в ~}{ }^{1}$, А.В. Кремлева ${ }^{1}$, А.М. Смирнов ${ }^{1}$, Д.А. Бауман ${ }^{1}$, \\ А.Е. Романов ${ }^{1,2}$, М.А. Одноблюдов ${ }^{1,3}$, В.Е. Бугров ${ }^{1}$ \\ ${ }^{1}$ Университет ИТМО, Санкт-Петербург, Россия \\ ${ }^{2}$ Физико-технический институт им. А.Ф. Иофффе РАН, Санкт-Петербург, Россия \\ ${ }^{3}$ Санкт-Петербургский политехнический университет Петра Великого, Санкт-Петербург, Россия \\ ฯ E-mail: dmitriipnv@gmail.com
}

Поступило в Редакцию 5 августа 2020 г.

В окончательной редакции 5 августа 2020г.

Принято к публикации 16 августа 2020г.

Сообщается об успешных экспериментах по выращиванию кристаллов бета-оксида галлия методом Чохральского. Исследовалось влияние состава ростовой атмосферы на кристаллическое совершенство материала. Показано, что для получения высококачественных оптически прозрачных кристаллов необходимо наличие в атмосфере роста около 5 vol.\% кислорода. Проведены рентгеноструктурный анализ и исследование спектров оптического пропускания выращенных кристаллов.

Ключевые слова: оксид галлия, вытягивание из расплава, метод Чохральского, кислородные вакансии.

DOI: 10.21883/PJTF.2020.22.50308.18499

В последние годы в мире сильно возрос интерес к новому широкозонному полупроводниковому материалу - бета-оксиду галлия $\left(\beta-\mathrm{Ga}_{2} \mathrm{O}_{3}\right)[1,2]$. Большая ширина запрещенной зоны $(4.9 \mathrm{eV})$, относительно высокая электронная подвижность (более $150 \mathrm{~cm}^{2} /(\mathrm{V} \cdot \mathrm{s})$, высокое напряжение пробоя $(8 \mathrm{MV} / \mathrm{cm})$, прозрачность в видимой и УФ-областях спектра делают этот материал весьма перспективным для множества приложений микро-, опто-, а также силовой электроники. Бета-оксид галлия может использоваться для создания приборов с рекордными характеристиками, таких, например, как МОП-транзистор (МОП металл-оксид-полупроводник) с напряжением пробоя более $1000 \mathrm{~V}$ [3], а также в качестве прозрачной проводящей подложки для эпитаксиального роста нитридов третьей группы [4].

Важным преимуществом оксида галлия перед нитридными полупроводниками ( $\mathrm{GaN}, \mathrm{AlN})$ является относительная простота его получения в виде объемных монокристаллов. В мире для выращивания кристаллов $\beta-\mathrm{Ga}_{2} \mathrm{O}_{3}$ используются такие широко известные методы, как метод Степанова [5], метод Чохральского [6,7], метод зонной плавки [8] и др. Однако рост оксида галлия из расплава осложняется химической нестабильностью этого материала при температуре плавления [6]. Это делает невозможным получение качественного материала в инертной атмосфере роста и требует введения в нее кислорода в количестве от нескольких единиц до нескольких десятков объемных процентов [7]. Наличие кислорода в атмосфере ростового реактора в сочетании с весьма высокой температурой плавления оксида галлия $\left(1850^{\circ} \mathrm{C}\right)$ накладывает существенные ограничения на материалы, используемые для изготовления тигля и других элементов оснастки (в подавляющем большинстве случаев для этого применяется иридий).

В настоящей работе сообщается об успешном опыте получения высококачественных монокристаллов бетаоксида галлия из расплава методом Чохральского. Проведено детальное исследование влияния атмосферы ростового реактора (парциального давления кислорода) на качество выращенных кристаллов.

Распространенным способом добавления кислорода при росте оксида галлия является использование двуокиси углерода $\left(\mathrm{CO}_{2}\right)$ в качестве ростовой атмосферы. При температуре плавления оксида галлия $\mathrm{CO}_{2}$ частично диссоциирует с выделением около 1 vol.\% $\mathrm{O}_{2}$ [9]. Преимуществом такого подхода является минимизация риска окисления деталей ростовой установки: свободный кислород возникает непосредственно над горячей поверхностью расплава. Однако таким образом невозможно получить в ростовой атмосфере концентрацию кислорода хотя бы несколько объемных процентов. Для достижения более высоких концентраций кислород необходимо добавлять в атмосферу реактора непосредственно.

Ростовые процессы осуществлялись в промышленной ростовой установке индукционного нагрева тигля „Ника-3“. В качестве исходного материала использовался порошкообразный $\mathrm{Ga}_{2} \mathrm{O}_{3}$, чистота реактива составляла 99.99\%(4N), тигель был изготовлен из Ir. Для затравок использовались кристаллиты $\mathrm{Ga}_{2} \mathrm{O}_{3}$, вырезанные из ранее полученных кристаллов, первичный рост которых осуществлялся на затравках из сапфира. В качестве ростовой атмосферы реактора использовались либо чистый $\mathrm{CO}_{2}$, либо смесь газов $\mathrm{Ar}$ и $\mathrm{O}_{2}$ при давлении около 1 bar; содержание $\mathrm{O}_{2}$ в смеси варьировалось в 


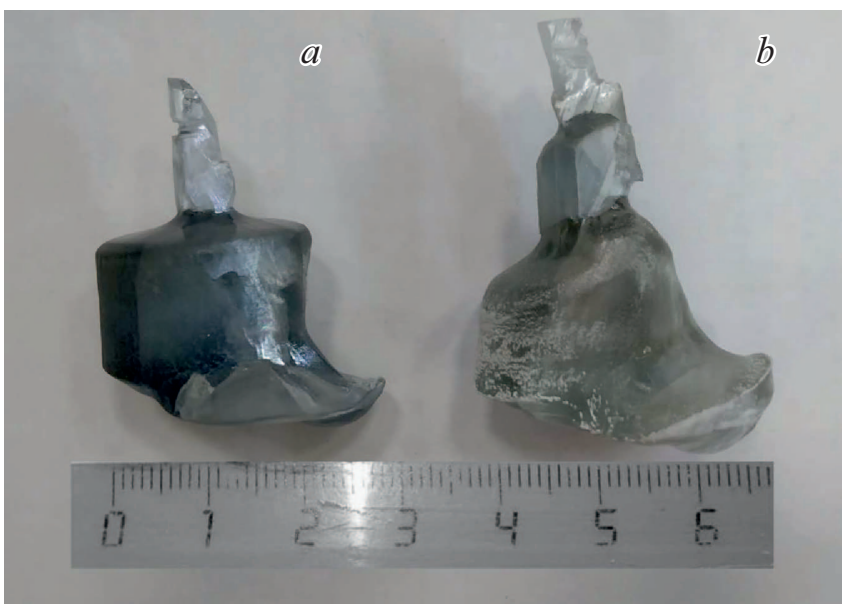

Рис. 1. Фотографии кристаллов $\beta-\mathrm{Ga}_{2} \mathrm{O}_{3}$, выращенных в aтмосфере $\mathrm{CO}_{2}(a)$ и $\mathrm{Ar}: \mathrm{O}_{2}(95: 5)(b)$.

диапазоне 0-10 vol.\%. Скорость вытягивания кристалла составляла $0.1-0.2 \mathrm{~mm} / \mathrm{min}$, скорость вращения затравки - 5-10 rpm. Детали конструкции ростовой зоны и процесса роста опубликованы нами ранее [10].

На рис. 1, $a, b$ приведены фотографии кристаллов, выращенных в атмосфере $\mathrm{CO}_{2}$ и $\mathrm{Ar}: \mathrm{O}_{2}(5 \%)$ соответственно. Из этого рисунка видно, что кристалл, полученный в атмосфере с 5\% содержанием кислорода, имеет лучшую прозрачность и визуальное качество материала. Дальнейшее увеличение содержания кислорода в атмосфере роста не приводит к визуальным изменениям цвета и качества кристаллов. Кристаллы получаются практически бесцветными, имеют форму, близкую к цилиндрической. Геометрические размеры - около $2 \mathrm{~cm}$ в диаметре и $2 \mathrm{~cm}$ в высоту. В верхней части видна исходная затравка, в нижней - асимметричный нарост, возникающий в момент отрыва кристалла от расплава.

Кристаллическое совершенство полученных кристаллов $\mathrm{Ga}_{2} \mathrm{O}_{3}$ было проанализировано с помощью метода рентгеноструктурного анализа на установке ДРОН-8 в щелевой конфигурации с острофокусной трубкой с медным анодом и сцинтилляционным детектором $\mathrm{NaI}$ (Tl) и Ni-фильтром $\beta$-излучения.

На рис. 2 приведена типичная кривая качания для отражения от плоскости (400) кристалла $\beta-\mathrm{Ga}_{2} \mathrm{O}_{3}$, выращенного в атмосфере $\mathrm{Ar}: \mathrm{O}_{2}$ с содержанием кислорода $5 \%$. Ширина кривой на полувысоте составляет около 220 arcsec. Увеличение содержания кислорода в атмосфере роста до 10\% не привело к сужению кривой качания.

На рис. 3 представлены спектры оптического пропускания кристаллов, выращенных в различных условиях. Из рисунка видно, что оптическое пропускание образцов, выращенных в условиях относительно большого содержания кислорода в атмосфере выше, чем для образца, выращенного при малом парциальном давлении кислорода (в атмосфере $\mathrm{CO}_{2}$ ), особенно в длинноволновой области спектра. На основе этого можно сделать вывод, что концентрация свободных носителей в кристалле уменьшается по мере увеличения парциального давления кислорода в атмосфере роста, видимо за счет уменьшения плотности точечных дефектов - кислородных вакансий [8].

Таким образом, в работе показано, что выращивание методом Чохральского из расплава позволяет получать высококачественные объемные кристаллы бета-оксида галлия. Одним из ключевых факторов, определяющих кристаллическое совершенство получаемого материала, является состав атмосферы ростовой камеры. Концентрация кислорода в ней должна составлять около 5 vol.\%. Дальнейшее увеличение содержания кислорода не приводит к видимым улучшениям кристаллического совершенства получаемых образцов и/или изменению в спектрах их оптического пропускания, но негативно

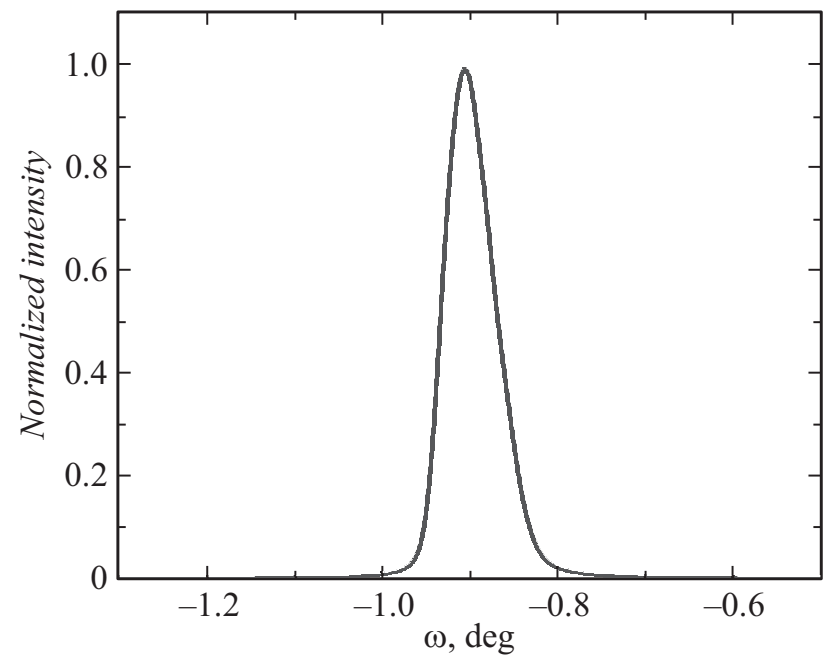

Рис. 2. Кривая качания для отражения от плоскости (400) кристалла $\beta-\mathrm{Ga}_{2} \mathrm{O}_{3}$, выращенного в атмосфере $\mathrm{Ar}: \mathrm{O}_{2}(95: 5)$.

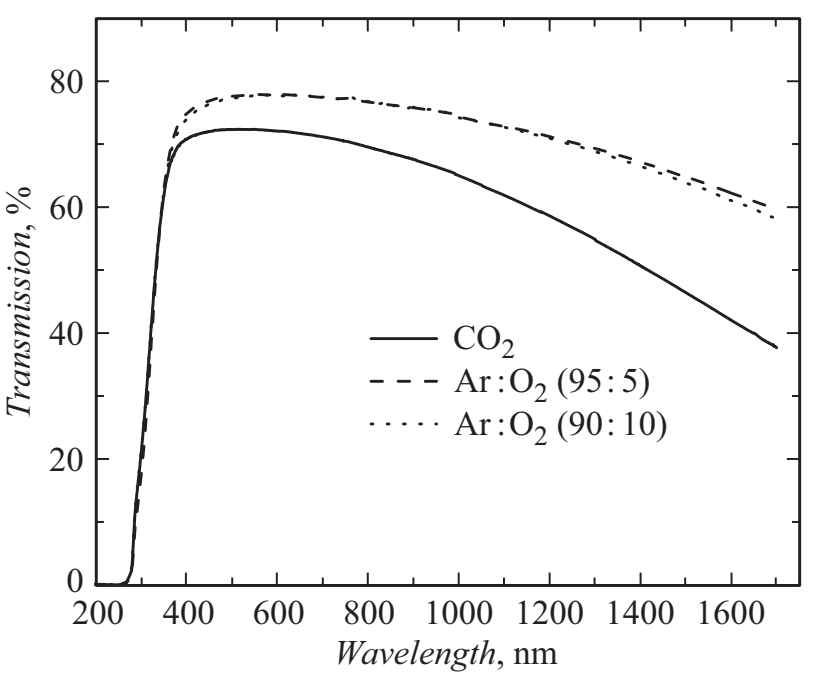

Рис. 3. Спектры оптического пропускания $\beta-\mathrm{Ga}_{2} \mathrm{O}_{3}$, выращенного в атмосфере $\mathrm{CO}_{2}, \mathrm{Ar}: \mathrm{O}_{2}(95: 5)$ и $\mathrm{Ar}: \mathrm{O}_{2}(90: 10)$. 
сказывается на сроке службы ростовой оснастки, изготовленной из иридия.

\section{Благодарности}

Авторы выражают благодарность Д.С. Кукушкину $(\mathrm{OOO} \mathrm{„Тидекс“})$ за помощь в измерении спектров оптического пропускания.

\section{Финансирование работы}

Работа выполнена при поддержке Российского научного фонда (проект № 19-19-00686).

\section{Конфликт интересов}

Авторы заявляют, что у них нет конфликта интересов.

\section{Список литературы}

[1] Pearton S.J., Yang J., Cary P.H., Ren F., Kim J., Tadjer M.J., Mastro M.A. // Appl. Phys. Rev. 2018. V. 5. N 1. P. 011301. DOI: $10.1063 / 1.5006941$

[2] Stepanov S.I., Nikolaev V.I., Bougrov V.E., Romanov A.E. // Rev. Adv. Mater. Sci. 2016. V. 44. N 1. P. 63-86.

[3] Hu Z., Nomoto K., Li W., Tanen N., Sasaki K., Kuramata A., Nakamura T., Jena T., Xing H.G. // IEEE Electron Dev. Lett. 2018. V. 39. N 6. P. 869-872.

[4] Villora E.G., Arjoca S., Shimamura K., Inomata D., Aoki K. $\beta-\mathrm{Ga}_{2} \mathrm{O}_{3}$ and single-crystal phosphors for high-brightness white LEDs and LDs, and $\beta-\mathrm{Ga}_{2} \mathrm{O}_{3}$ potential for next generation of power devices // Oxide-based materials and devices V. International Society for Optics and Photonics, 2014. V. 8987. P. 89871 U.

[5] Kuramata A., Koshi K., Watanabe S., Yamaoka Y., Masui T., Yamakoshi S. // Jpn. J. Appl. Phys. 2016. V. 55. N 12. P. 1202A2. DOI: 10.7567/JJAP.55.1202A2

[6] Galazka Z., Uecker R., Klimm D., Irmscher K., Naumann M., Pietsch M., Kwasniewski A., Bertram A., Ganschow S., Bickermann M. // ECS J. Solid State Sci. Technol. 2017. V. 6. N 2. P. Q3007-Q3011.

[7] Baldini M., Galazka M., Wagner G. // Mater. Sci. Semicond. Proc. 2018. V. 78. P. 132-146.

[8] Hossain E., Kulkarni R., Mondal R., Guddolian S., Azizur Rahman A., Thamizhavel A., Bhattacharya A. // ECS J. Solid State Sci. Technol. 2019. V. 8. N 7. P. Q3144-Q3148.

[9] Galazka Z., Irmscher K., Uecker R., Bertram R., Pietsch M., Kwasniewski A., Naumann M., Schulz T., Schewski R., Klimm D., Bickermann M. // J. Cryst. Growth. 2014. V. 404. P. 184-191. DOI: 10.1016/j.jcrysgro.2014.07.021

[10] Butenko P.N., Panov D.I., Kremleva A.V., Zakgeim D.A., Nashchekin A.V., Smirnova I.G., Bauman D.A., Romanov A.E., Bougrov V.E. // Mater. Phys. Mech. 2019. V. 42. N 6. P. $802-807$. 